\title{
Daniel Alcides Carrión García en la Cripta de los Héroes de la Guerra de 1879
}

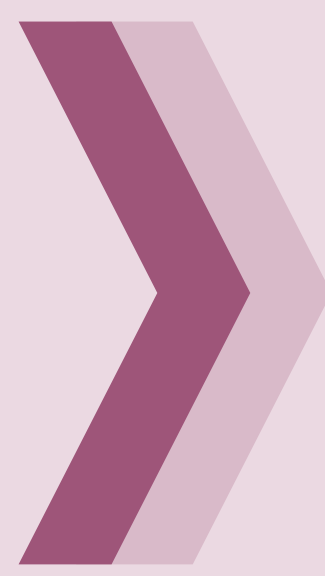

\section{Daniel Alcides Carrión García in the Crypt of the Heroes of the War of 1879}

\section{Gustavo Ernesto Delgado-Matallana ${ }^{1}$}

1. Médico cardiólogo y geriatra. Expresidente de la Asociación de Historia de la Medicina Peruana. Presidente emérito de la Asociación Médica Peruana "Daniel Alcides Carrión". Profesor emérito de la Universidad Nacional Mayor de San Marcos. Estudioso de la vida de Daniel Alcides Carrión-García.

\section{RESUMEN}

Daniel Alcides Carrión García es considerado de manera oficial mártir de la Medicina, héroe nacional, maestro de la Medicina peruana, patrono de la Medicina nacional. Desde el 24 de marzo de 2015, su nombre está en la Cripta de los Héroes de la Guerra de 1879. Luego de veintiún años de tesonera e indesmayable labor y trámite, finalmente se consiguió que el Ministerio de Defensa de la República del Perú realice una ceremonia mediante la cual se inscribió el nombre de Carrión en una placa mural en la Cripta de los Héroes, como homenaje a perpetuidad por su paradigmático heroísmo. Solo se colocó la placa con su nombre, porque no se ha podido identificar ni localizar los restos mortales de nuestro héroe. En la exégesis historiográfica del Daniel A. Carrión se enuncian dos sucesos históricos que lo exaltan como patriota y científico, los cuales me permito recordar.

Palabras clave: enfermedad de Carrión; Daniel A. Carrión; patriota; científico; Cripta de los Héroes; homenaje

\begin{abstract}
Daniel Alcides Carrion Garcia is officially considered a martyr of Medicine, a national hero, master of the Peruvian Medicine, patron of the National Medicine. Since March 24, 2015, his name is in the Crypt of Heroes. After twenty-one years of tenacious and unflagging work and process, finally the Ministry of Defence of the Republic of Peru perform a ceremony in which the name Carrion enrolled in a wall plate in the Crypt of Heroes of the "Pacific War", as a tribute in perpetuity for his paradigmatic heroism. Only the name plaque was placed, because it has not been possible to identify and locate the mortal remains of our hero. In the historiographical exegesis of Daniel A. Carrion two historical events that exalt him as a patriot and scientist are set, which I remind.
\end{abstract}

Keywords: Carrion's disease; Daniel A. Carrion; patriot; scientific; Crypt of Heroes; tribute 


\section{CARRIÓN PATRIOTA}

\section{Exordio}

En el ciclo universitario de Daniel A. Carrión (18 abril de 1877 - 5 octubre de 1885), el Perú estuvo inmerso en la llamada Guerra del Salitre, del Pacífico o contra Chile en 1879 (5 abril de 1879 - 20 octubre de 1883). El antecedente de este conflicto bélico fue la constante y preparada amenaza expansionista de Chile para invadir Bolivia y Perú, lo que obligó a estos países a concertar secretamente un Tratado de Alianza Defensiva Perú-Bolivia, suscrito en Lima el 6 de febrero de 1873 por el representante del Perú, doctor José de Riva Agüero, y el de Bolivia, don Juan de la Cruz Benavente.

Leal a su compromiso, el Perú protestó ante el gobierno chileno por la sorpresiva e injusta invasión y ocupación de los territorios bolivianos Antofagasta, Mejillones y Caracol el 14 de febrero de 1879. A este requerimiento se sumaron, el 16 de marzo de 1879 , los graduados y alumnos de las Facultades de la Universidad de San Marcos y de las Escuelas de Construcción y Minería, con un histórico pronunciamiento contra el alevoso asalto con menosprecio de la Ley Internacional y la civilización de nuestra época. La insólita respuesta de Chile fue declarar la guerra al Perú el 5 de abril de 1879.

\section{Alistamiento de Carrión}

La participación patriótica de Daniel A. Carrión se inició en 1880. Ya había terminado la "Campaña del mar" con la heroica inmolación del almirante Miguel Grau Seminario, quien con el emblemático monitor "Huáscar" se enfrentó a una premeditada y poderosa flota chilena y pasó a la inmortalidad en Punta Angamos el 8 de octubre de 1879, y la "Campaña terrestre" había tenido una valerosa y patriótica resistencia en la "Epopeya de Arica" el 7 de junio de 1880, donde el ínclito coronel Francisco Bolognesi Cervantes pasó a la eternidad con heroísmo glorioso.

El escenario era propicio para poner en práctica el plan previsto por la tropa chilena de conquistar y posesionarse de la capital. Ante la precaria situación en que quedó el ejército regular del Perú, y frente a la inminente invasión, fue necesario disponer la defensa de Lima, para lo cual el dictador Nicolás de Piérola promulgó el decreto supremo del 17 de junio de 1880 convocando a las armas a todos los habitantes de Lima y a los peruanos en general entre 16 y 60 años de edad para constituir el Ejército de Reserva, al que se sumaron los sobrevivientes de acciones anteriores.

Existen varios documentos en los que figura Carrión como partícipe de la "Gesta de Lima":

a) El "Resumen cronológico de los hechos históricos de la Guerra del Pacífico (1879-1881)"1 indica en el orden numérico $\mathrm{N}^{\circ} 65$ lo siguiente: ACCIÓN, convocatoria de Reservas; FECHA, 03 dic. 1880; LUGAR, Lima; PROTAGONISTAS, Nicolás de Piérola, Federico Villarreal, comandante Pedro Ruiz Gallo, doctor Manuel Candamo, doctor Francisco García Calderón, Daniel Alcides Carrión, y otros. Esta es una mención honrosa que se hace a Carrión cuando solo cursaba el primer año en la Facultad de Medicina de San Fernando.

b) Existe una composición fotográfica del Batallón "23 de diciembre" en la que figuran los retratos del primer jefe coronel temporal doctor Francisco M. Fernández y de los oficiales de la plana mayor y de Daniel A. Carrión como abanderado con el uniforme militar de subteniente temporal. ${ }^{1}$

c) Al enunciar la relación completa de los comandos, batallones y fuerzas rurales de la defensa de Lima, ${ }^{1}$ figura el Batallón $\mathrm{N}^{\circ} 36$, que es el mismo Batallón " 23 de diciembre", con el mismo jefe, plana mayor y Daniel A. Carrión como abanderado subteniente temporal.

Así se demuestra que Carrión estuvo alistado, acuartelado y entrenado en el nuevo Ejército de Reserva.

\section{Batallas de San Juan y Miraflores}

Fue en la "Campaña de Lima" que se proyectó la defensa de la capital. Piérola dispuso la organización y trazado de dos frentes que actuarían sucesivamente en San Juan y Miraflores.

Batalla de San Juan, 13 de enero $\mathbf{1 8 8 1}$. Se ordenó de acuerdo al "Esquema de organización y 
disposición de la fuerzas peruanas en la línea de defensa de San Juan". ${ }^{1}$ Actuaron cuatro cuerpos del ejército. El III Cuerpo de Ejército en el flanco izquierdo, comandado por el coronel Justo Pastor Dávila, con 4200 hombres, comprendía siete batallones: "Libertad", "Piura", "23 de diciembre", Cazadores de Cajamarca”, "Unión”, "Cazadores de Junín", "N 40 de la Reserva" y cinco columnas de la Guardia Civil.

Batalla de Miraflores 15 de enero de 1881 . Se planificó de acuerdo al "Esquema de organización y disposición de las fuerzas peruanas en la línea defensiva de los reductos". ${ }^{1}$ A las fortificaciones se les denominó "reductos" y el Ejército de Reserva se dispuso en tres cuerpos del ejército, estando el tercero al mando del coronel Justo Pastor Dávila defendiendo los reductos 6,7 y 8 con 2000 hombres y seis cañones de los batallones: "Unión", "Piura”, "23 de diciembre" y "Cazadores de Cajamarca".

Con todo lo mencionado se evidencia fidedignamente que Carrión participó en el Ejército de Reserva, en ambas batallas, integrando el batallón "23 de diciembre" con el grado de subteniente temporal. En esa época cursaba el segundo año en la Facultad de Medicina de San Fernando. Su misión patriótica y humanitaria la prodigó con riesgo de su vida en el fragor del combate; como practicante de Medicina en las ambulancias de guerra, trasladando heridos, dándoles ayuda física y afectiva, colaborando en sus curaciones y, según lo dispuesto, recogía soldados inmolados para ayudar a sepultarlos en el mismo campo de combate.

Así, con la misión cumplida en la defensa del honor de la Patria, se distinguió como un héroe sobreviviente, al igual que Andrés A. Cáceres y otros distinguidos patriotas.

\section{CARRIÓN CIENTÍFICO}

\section{Dos procesos patológicos enigmáticos}

Desde tiempos inmemoriales existen en los valles interandinos de la vertiente occidental de los Andes Centrales dos procesos patológicos oriundos del Perú, que se presentan entre 800 y $2000 \mathrm{~m}$ de altitud. Su presencia requiere de un sistema ecológico telúrico, con un terreno que propicie el hábitat para el desarrollo de un agente trasmisor que afecta al factor humano, portador y receptor.

Por cuatro centurias, hasta finales del siglo XIX, solo se identificó claramente uno de ellos, caracterizado por la erupción cutánea de tumores de diferentes tamaños y morfologías, de ubicación focal o difusa, de variable tiempo de aparición, de duración inconstante y generalmente de pronóstico benigno. A esta entidad se le denominó con las voces quechuas kccepo o sirky, después "berrucas", "verrugas" y en 1858 el doctor Tomás Salazar le llamó "verruga andícola".

El otro proceso, de mayor gravedad, cuando se presentaba, ocurría en los mismos valles interandinos verrucógenos; su identificación no era clara porque se confundía con otros procesos infecciosos. Fue en los años 1871, 1872 y 1873, cuando se construía el ferrocarril central, que se presentó alarmante y en gran proporción, en el tramo comprendido entre San Bartolomé (Km 71, a 1533 m de altitud) y Surco (Km 91, a 2000 m de altitud), que se encontró abruptas montañas con terreno anfractuoso, escabroso, de difícil acceso, con escarpes casi verticales, que obligó al ingeniero Ernesto Malinowski a construir un puente de enlace para continuar la ferrovía.

Este cañón geológico profundo en la quebrada de Huarochirí fue propicio para el desarrollo del agente vector "titira" (insecto hembra, que Charles Townsend en 1913 lo identificó como un díptero hemófago y lo clasificó como Phlebotomus verrucarum; desde 1948 se denomina Lutzomia verrucarum) y una explosión demográfica de más de 17000 trabajadores de distintas etnias.

En este apropiado sistema ecológico telúrico, brotó una epidemia accidental, de gran nocividad y rápida propagación caracterizado por alzas febriles irregulares, anemia intensa progresiva, que era incompatible con la vida y estado general depredante, que llevó a la muerte a más de 7000 personas. Esta es la primera vez que se identificó este proceso, al cual el doctor Nicanor Pancorvo en 1872 lo individualizó como "fiebre de La Oroya".

La conclusión histórica que se manejaba en la segunda mitad del siglo XIX era que la fiebre de La Oroya y verruga andícola, eran, aparentemente, dos entidades sin vinculación y de causas desconocidas. 


\section{Presencia de Carrión}

Paralelamente, y en época contemporánea a estos acontecimientos, surge la figura predestinada de Carrión que en sus viajes Cerro de Pasco - Lima y viceversa, durante sus vacaciones anuales, en los meses de diciembre y marzo, pasó por tres momentos históricos. De 1873 a 1876, cuando cursaba la educación secundaria en el Colegio "Nuestra Señora de Guadalupe", tuvo conocimiento de los problemas sanitarios enigmáticos que afectaban a la población altoandina y mostró gran interés, indudablemente influenciado por el factor genético de su saga paterna (su abuelo fue el médico ecuatoriano doctor Francisco Carrión Riofrío y su padre, también ecuatoriano, fue el médico doctor Baltazar Carrión Torres).

De 1877 a 1879, en su educación superior en la Universidad de San Marcos en la Facultad de Ciencias Biológicas, Físicas y Matemáticas, en la Sección de Ciencias Naturales, adquirió conocimientos científicos exactos y razonados de los sucesos, incrementando su interés en el estudio de estos procesos sanitarios. De 1880 a 1885, en la Facultad de Medicina de San Fernando adquirió sólidos conocimientos médicos nosológicos y epidemiológicos y su perseverancia tiene la opción privilegiada de recorrer las zonas verrucógenas de alta incidencia, visitar el Hospital Hope (Esperanza) en Cocachacra, instalado por la empresa constructora, dialogar con los pacientes, revisar y elaborar nuevas historias clínicas.

En 1883 y 1885 escribió el opúsculo "Apuntes sobre verruga", en el que relata su experiencia, establece que en su incidencia no influye la edad, sexo ni raza, pero sí es predisponente una enfermedad preexistente o la desnutrición. Establece que en su evolución hay cuatro períodos: 1) incubación, que se definirá cuando la práctica de las inoculaciones extienda su esfera de acción; 2) invasión, erupción, comienza a presentarse en época variable entre los 20 dias siguientes del envenenamiento invasivo hasta los seis y aún ocho meses posteriores... es el fenómeno patognomónico de la enfermedad...se presenta en la superficie de la piel y bajo de ella en forma subcutánea... otras veces en mucosas y vísceras internas; 3 ) desecación, regresión o atrofia de los tumores verrucosos y 4) anemia.
Al tratar la anemia refiere que se desarrolla más o menos violentamente y con mayor o menor energía según los individuos... El agente verrucoso entra en la sangre alterando la nutrición hasta producir caquexia. En relación al diagnóstico escribe: Un dato seguro y fiel que pueda hacernos sospechar la existencia de la verruga, antes de la erupción, es el conocimiento dónde ha estado o pasado el enfermo.

\section{Influencias culturales}

En la segunda mitad del siglo XIX ocurren motivaciones que impulsan a Carrión a su determinación científica. El positivismo, doctrina filosófica fundada por Augusto Comte, afirma que la verdad de los conocimientos solo se obtiene cuando los hechos son verificados y reproducidos por la experimentación; rechaza los principios metafísicos negativos y alejados de la realidad concreta. La Ilustración deja una corriente cultural que revisa la concepción del hombre y del mundo en todos los terrenos y con la razón tiene la facultad de discurrir, argumentar y demostrar una verdad, alejada de los principios tradicionales y los dogmas de la fe.

Predomina el postulado del fisiólogo francés Claude Bernard, padre de la experimentación, que solo reconoce el saber que está basado en el método experimental. Es muy interesante el postulado del naturalista francés George Curier que establece que: Para conocer al hombre hay que estudiarlo en el hombre. También, en revistas médicas aparecen publicaciones de casos de inoculaciones experimentales en humanos con especímenes patológicos de sífilis, pústula maligna, osteomielitis, cólera y otros, con fines de investigación médica.

La liberación de los puertos del litoral peruano, cautivos por la invasión chilena de 1879 a 1883, suscitó la llegada devaliosainformación europea en todos los aspectos del saber humano; en el avance de la bacteriología se tuvo pleno conocimiento de que innumerables enfermedades infecciosas tienen como agente etiológico un microorganismo patógeno, con lo cual se va desechando la creencia que los ambientes miasmáticos, mefíticos pútridos y la calidad de ciertas aguas eran causas de las enfermedades. 


\section{Tesis de bachiller en medicina}

Este acervo impresionante, valioso y único, nutre el interés científico de Carrión, su obsesión por desentrañar el enigma de este complejo sanitario nacional y su perseverancia apasionada en bien de la humanidad. Carrión cursaba el sexto año en la Facultad de Medicina de San Fernando y ya tenía terminado su trabajo académico sobre la verruga peruana para presentarlo como tesis para obtener el grado de bachiller en Medicina, con la conclusión que la verruga andicola es una enfermedad infecciosa producida por un microorganismo patógeno y que es inoculable.

\section{Inoculación}

En esta circunstancia, en 1885 , surge un momento crucial: la investigación de Carrión sobre la verruga andícola estaba lista para presentarse y así obtener el grado de bachiller en Medicina, cuando la Academia Libre de Medicina, al instalarse solemnemente el 29 de julio de 1885, convocó a un concurso: "Etiología, anatomía patológica y distribución geográfica de la verruga peruana". Se otorgó el plazo de un año para la presentación de los postulantes.

Asimismo, se publicó en Alemania un artículo del doctor Vicente Izquierdo* sobre "Histopatología de la verruga peruana" en Virchow Arch. (Bd. 99) 1885. Ante esta disyuntiva Carrión, en un sesgo patriótico, expresa: Los chilenos nos han ganado en la guerra, pero no nos ganarán en la ciencia. Con imaginación coherente se puede presumir que Carrión optó por practicarse la inoculación experimental para verificar, en su propio cuerpo, su verdad científica.

Con este objetivo, en un acto consciente, voluntario, científico y de mucho valor, Carrión llevó a la acción su propósito. El diario de su experimentación lo inicia así: El 27 de agosto de 1885, a las 10 a.m., obtuve (no sin dificultad) de mi amigo el doctor Evaristo M. Chávez, que me practicara cuatro inoculaciones; dos en cada brazo cerca del sitio en que se hace la vacunación. Dichas inoculaciones se hicieron con la sangre inmediatamente extraída por rasgadura de un tumor verrucoso de color rojo situado en la región superciliar derecha del enfermo Carmen Paredes acostado en la cama $N^{\circ} 5$ de la Sala Nuestra Señora de las Mercedes, perteneciente al Servicio del señor doctor Villar. Testigos de este acto heroico fueron los doctores Leonardo Villar y Evaristo Chávez, el interno Julián Arce, el externo Sebastián Rodríguez y el barchilón Jesús M. Farfán.

Por esto, propongo que el 27 de agosto, fecha de la heroica inoculación a Carrión, se declare por Ley "Día del inicio de la medicina experimental en el Perú".

Transcurridos veintiún días de la incubación, el 17 de septiembre inició su enfermedad con un cortejo sucesivo de síntomas y signos físicos y mentales, que él mismo anotó en su diario. El 26 de septiembre escribió: A partir de hoy día me observarán mis compañeros pues, por mi parte, confieso sería difícil hacerlo. El curso de la enfermedad, cada vez más agravante, lo llevó a un estado anémico de evolución muy rápida que era casi incompatible con la vida y dominaba el cuadro clínico; la anemia fue comprobada por el recuento globular que le practicó el doctor Ricardo L. Flores el 3 de octubre -el primero realizado en el Perú- con el resultado de un millón cincuenta mil glóbulos rojos por mL.

Un suceso significativo y transcendente ocurre cuando el 2 de octubre Carrión, en un momento de plena lucidez y con clara percepción y entendimiento, se dirige a sus condiscípulos y les dice: Hasta hoy había creído que me encontraba tan solo en la invasión de la verruga como consecuencia de mi inoculación, es decir, en aquel período anemizante que precede a la erupción, pero ahora me encuentro firmemente persuadido de que estoy atacado por la fiebre de que murió nuestro amigo Orihuela, quien fue diagnosticado de fiebre de La Oroya; he aquí la prueba palpable de que la fiebre de La Oroya y la verruga reconocen el mismo origen, como una vez le oi decir al doctor Alarco. 
Con su convicción, dos días después, el 5 de octubre, Carrión ofrendó su vida en una aventura épica hacia la muerte, sufriendo con estoicismo extraordinario, con gran fortaleza de ánimo y control de su propia sensibilidad, pasando a la inmortalidad con heroísmo glorioso en bien de la humanidad.

\section{EPÍLOGO}

1. El 16 de octubre de 1885 dos entidades médicas, las únicas existentes en el Perú, Sociedad Médica "Unión Fernandina" y Academia Libre de Medicina, acordaron, en sendas ceremonias, declarar a Daniel A. Carrión "Mártir de la Medicina", con lo cual figura en el martirologio universal, víctima de su causa.

2. El 5 de octubre de 1886 la Asociación Médica "Unión Fernandina", en solemne ceremonia, con distinguida y erudita audiencia, aprobó por aclamación, la propuesta del condiscípulo de Carrión, Mariano Alcedán para que los procesos unificados se denominen "enfermedad de Carrión", con lo cual el Perú y Carrión enriquecieron la patología médica.

3. En 1985, centenario de la inmolación de Carrión, se rindió homenaje y se colocó su busto en las siguientes instituciones: Instituto de Historia de la Medicina en la Facultad de Medicina de la Universidad de Bonn (RFA), incorporándolo como "miembro ilustre" y con adhesión del rector de la Universidad de Dusseldorf (RFA); el antiguo local de la Facultad de Medicina de París (Universidad René Descartes); el Instituto de Medicina Tropical de Amberes; el Parque de Retiro de Madrid; el Hospital de la Caridad de Berlín Oriental, en la Sala Roberto Kosh; en el edificio de Organización Panamericana de la Salud; en Washington D.C. También se le rindió homenaje en la Academia de Medicina de Madrid; en Valparaíso, Chile; la Caja de Seguro Obrero designó la Sala de Clínica Dermatológica con la denominación epónima; en Bogotá, Colombia, la Universidad Nacional de Colombia designó uno de sus locales con el nombre de Carrión.

4. En 1991 el Congreso de la República aprobó la Ley que declaró a Daniel A. Carrión "Héroe nacional", la cual fue promulgada por el Ejecutivo el 7 de octubre de 1991 con la Ley $\mathrm{N}^{\circ}$ 25342. Así se le identificó como el "Primer héroe civil en el Perú", el "Único héroe médico nacional" y "Primer médico héroe mundial".

5. Se homologó a Carrión con los héroes nacionales: el 23 de julio de 2003, en el local del Congreso de la República, se inauguró un recinto que se denominó Sala de Comisiones "Daniel A. Carrión" y se colocó su óleo. El 2 de octubre de 2006, en la Benemérita Sociedad Fundadores de la Independencia, Vencedores del Dos de Mayo 1866 y Defensores Calificados de la Patria, se colocó el óleo de Carrión en la Sala de Guerra de 1879. El año 2006, el Centro de Estudios Históricos Militares del Perú incorporó a Daniel A. Carrión en la Galería de los Héroes Nacionales.

6. La Ley $\mathrm{N}^{\circ} 27794$, del 24 de julio de 2002, lo declaró "Maestro de la Medicina peruana".

7. La Ley $\mathrm{N}^{\circ} 27799$, del 29 de octubre de 2011, oficializó el 5 de octubre, fecha de inmolación de Carrión como "Día de la Medicina peruana", enalteciéndolo como "Patrono de la Medicina nacional".

8. La Ley $\mathrm{N}^{\circ} 30023$, del 21 de mayo de 2013, declaró el 13 de agosto, día del nacimiento de Carrión, "Día nacional de la salud y del buen trato al paciente".

9. El 26 de enero de 2015, el Ministerio de Defensa del Perú aprobó la colocación de una placa mural en homenaje a Carrión en el interior de los muros de la Cripta de los Héroes.

10. El 24 de marzo de 2015 el presidente emérito de la Asociación Daniel A. Carrión, con la aprobación del Ministerio de Defensa, invitó y presidió la impresionante ceremonia de inscripción del nombre de Carrión en una placa mural en la Cripta de los Héroes, como homenaje y perpetuidad de su paradigmático heroísmo.

\section{REFERENCIAS BIBLIOGRÁFICAS}

I. Comisión Permanente de la Historia del Ejército del Perú. Gesta de Lima 188I - 13/15 enero 198I. Lima, Perú: Ministerio de Guerra; 1981. 


\section{Acta Médica Perwana}

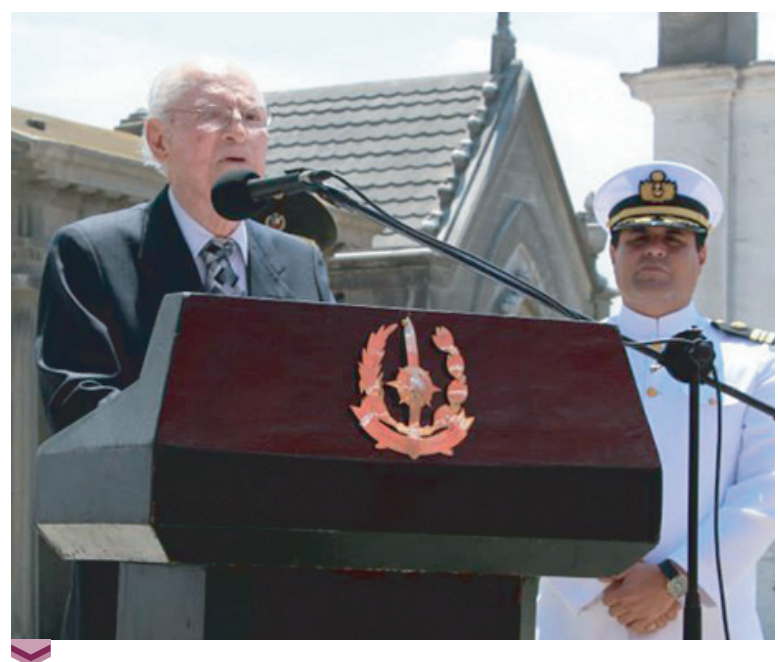

Foto 1. Discurso de orden del Dr. Gustavo Delgado Matallana, en el que narró amenamente la vida de nuestro ahora héroe nacional y las peripecias por las que pasó nuestro mártir para lograr la cura de la verruga peruana, fiebre de la Oroya o enfermedad de Carrión.

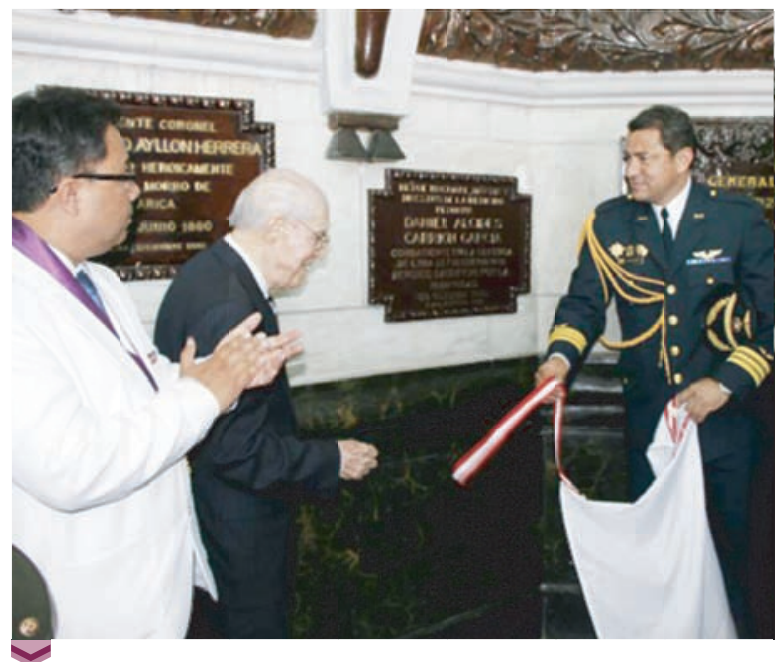

Foto 2. Momento de la develación de la placa de inscripción del Héroe Nacional, Mártir y Maestro de la Medicina Peruana Daniel Alcides Carrión García, en la Cripta de los Héroes de la "Guerra del Pacífico". Esta develación estuvo a cargo del Dr. Gustavo Delgado Matallana y el representante del Ministro de Defensa, el Comandante de la Fuerza Aérea del Perú Milko Klepatzky Reyna.

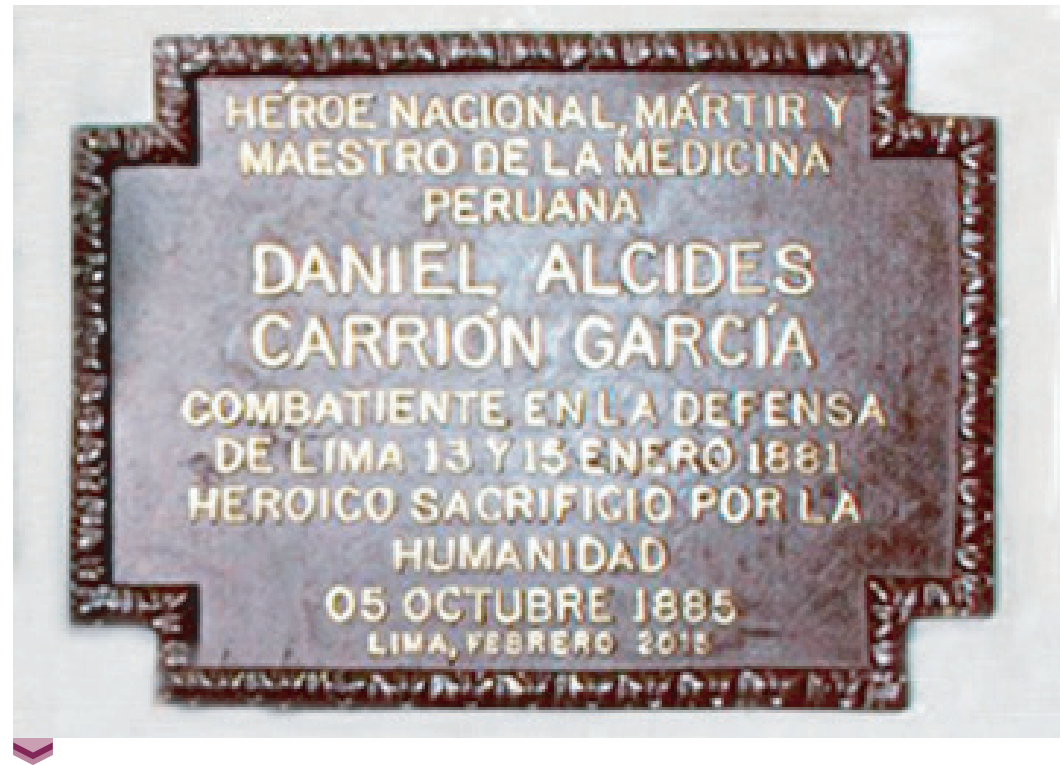

Foto 3. Placa mural en la Cripta de los Héroes de la "Guerra del Pacífico" con el nombre de Daniel Alcides Carrión García, como homenaje a perpetuidad por su paradigmático heroísmo. Se puede leer: "Héroe nacional, Mártir y maestro de la medicina peruana - Daniel Alcides Carrión García - Combatiente en la defensa de Lima 13 y 15 de enero 1881 - Heroico sacrificio por la humanidad - 5 octubre 1885. Lima, febrero 2015."

\section{Correspondencia}

Dr. Gustavo Ernesto Delgado-Matallana gustavodelgadomatallana@yahoo.es

Fecha de recepción: 21 de mayo de 2015

Fecha de aceptación: 3 de junio de 2015 